\title{
GEOGRAFIA NA PRÁTICA PEDAGÓgICA: A PAISAGEM COMO PONTO DE PARTIDA
}

Geografía em la práctica pedagógica: La paisaje como punto de partida

Mariana Zerbone Alves de Alburquerque

Professora do Departamento de História da UFPE

mzerbone@hotmail.com

Artigo recebido em 19/05/2014 e aceito para publicação em 16/06/2014

DOI: 10.12957/tamoios.2014.10139

RESUMO Neste presente artigo busca-se refletir acerca do papel da geografia no ensino básico frente a atual dinâmica das ações que produz e transforma os espaços de forma voraz, associada ao desenvolvimento das técnicas e de novas tecnologias, gerando a difusão de informação em larga escala. No entanto, percebe-se que historicamente há uma dificuldade de articulação de embasamento teórico-metodológico da geografia como ciência à prática pedagógica da geografia como disciplina escolar, em que a ciência avançou para uma análise crítica da realidade, enquanto que no âmbito escolar predomina o ensino de uma geografia tradicional. Deste modo, as reflexões aqui expostas tendem para a apropriação das categorias de análise da geografia como possibilidade de aproximação da teoria com a prática, tendo a paisagem como ponto de partida no processo de ensino-aprendizagem no âmbito escolar, pois a partir da análise da paisagem pode-se revelar as contradições inerentes à produção do espaço.

Palavras-chave: Geografia; Paisagem; Prática Pedagógica; Perspectivas Teóricometodológicas

RESUMEN En el presente artículo pretende reflexionar sobre el papel de la geografía en las escuelas ya que la dinámica actual de las acciones que produce y transforma los espacios és tan voraz, y asociadas con el desarrollo de las técnicas y las nuevas tecnologias facilitan la difusión de la información en gran escala. Sin embargo, se considera que en la historia de la geografía existe una dificultad de articulación de la formación teórico-metodológica como ciencia a la práctica pedagógica de la geografía como disciplina escolar, en la que la ciencia ha progresado a un análisis crítico de la realidad, mientras que en la escuela predomina la enseñanza de la geografía tradicional. De esta manera, las ideas expuestas aquí tienden para la el uso de las categorías de análisis de la geografía como posibilidad de aproximación de la teoría con la práctica, con el paisaje como punto de partida en proceso de enseñanza-aprendizaje en la escuela, ya que, desde el análisis del paisaje puede revelar las contradicciones inherentes a la producción de espacio.

Palavras-chave: Geografía; Paisaje; Práctica Pedagógica; Perspectivas; Teóricometodológicas 
A geografia como disciplina, antes de mais nada, é indispensável para a compreensão da realidade, do presente. É ela que vai fazer a aproximação do aluno com o meio, e com o que é vivido cotidianamente. É através dela que teremos as impressões e percepções referentes ao espaço, em diferentes escalas, desde o espaço vivido até o espaço global, e suas inter-relações.

A geografia serve para entender como a sociedade organiza seu espaço. Para o senso comum a geografia é entendida como saber se localizar no espaço, conhecer o nome dos lugares, as nomenclaturas de relevo e clima. Mas este conjunto de aspectos conhecidos pelo senso comum é o que foi trabalhado como geografia nas escolas por muito tempo. No entanto, para se entender os fenômenos do presente é preciso fazer uma análise do processo, ou seja, desvendar quais os fatores que influenciaram na materialização do mundo como é hoje, ou seja, da inter-relação sociedade-natureza.

Contudo, com a velocidade das ações e o avanço das técnicas, principalmente dos meios de comunicação, tem-se produzido em escala global um contingente enorme de informação como nunca se viu na história da humanidade. E essa nova dinâmica das ações que produz e transforma os espaços de forma voraz, torna-se um grande desafio para aos professores de geografia, visto o objetivo da geografia de compreender a realidade especializada em diferentes escalas. Desafio tanto no sentido de dar conta de toda a informação que é produzida, criando uma necessidade de constante atualização dos professores para responder à demanda dos alunos que tendem a estar cada vez mais informados, como também no sentido de que a geografia não teria mais vez como disciplina, pois esses "conhecimentos gerais" antes considerados uma especificidade da geografia, agora são disponibilizados pelos meios de comunicação de fácil e rápida de ser encontrada.

De acordo com Ana Fani A. Carlos (2009), as mudanças no mundo moderno requerem explicação. E nesse sentido, ela ainda indaga "Quais as possibilidades da geografia na construção de uma explicação capaz de esclarecer os conteúdos desses novos processos?" (CARLOS, 2009, p. 77 ). A partir desta atual dinâmica dos processos mundiais surgem outros questionamentos no âmbito da geografia escolar: qual seria o papel dos professores de geografia frente a essa nova conjuntura? Como pensar em perspectivas teórico-metodológicas para o ensino da geografia no século XXI? Que tipo de prática pedagógica deve ser selecionada para o ensino da geografia na "era da informação e das tecnologias"? Nesse sentido, surge a necessidade, aqui proposta, de compreender o papel da geografia como disciplina escolar na contemporaneidade, a fim de identificar perspectivas teórico-metodológicas que deem suporte à prática pedagógica no ensino da geografia.

O que se percebe é que a geografia vem passando por diversas transformações teórico-metodológicas desde quando se consolida como ciência em meados do século XIX, dando origem a diferentes correntes de pensamento da geografia: tradicional, teórico-quantitativa e crítica. No entanto o ensino da geografia nas escolas não sofreu grandes transformações no decorrer do tempo, não acompanhando as novas perspectivas teóricometodológicas elaboradas da geografia enquanto ciência.

Na perspectiva atual de uma geografia crítica, esta deveria se vista como a disciplina escolar capaz de ajudar a compreender as relações sociais que se estabelecem no espaço, ou seja, um tomar da consciência da realidade. No entanto, percebe-se que isto não vem acontecendo, a geografia escolar se consolidou como aquela de descrição dos lugares, buscando identificar todos os elementos da Terra, físicos e naturais, de forma sintética, não analítica e desarticulada. Segundo Jean-Michel Brabant (2008), o objetivo dessa geografia ensinada nas escolas não é raciocinar sobre um espaço e sim fazer dele um inventário. Isso tudo tem uma lógica, segundo Ariovaldo Umbelino de Oliveira (2008), a escola tem um papel ideológico, com isto o objetivo da escola na 
conjuntura do capital não é de formar cidadãos que possam pensar e discutir sobre suas condições e seus direitos, mas sim de formar uma mão-de-obra qualificada necessária à dinâmica produtiva capitalista.

A geografia, segundo José William Vesentini (2008), pode ser tanto um instrumento de dominação como de libertação, depende de como esta é abordada nas escolas. Mas o que se percebe é que essa geografia ainda hoje apresentada nas escolas remete ainda à Geografia Tradicional fundada no século XIX. Neste momento da história a Geografia serviu de suporte para as ideias imperialistas que se estabeleciam com a consolidação do sistema capitalista de produção. Havia a necessidade de se conhecer os lugares, de obter todo seu inventário, a fim de expandir e delimitar as fronteiras, fundamentada na teoria do espaço vital elaborada por Ratzel, que afirma que há uma relação direta entre povo e o solo, ocasionando na delimitação dos territórios, a fim de justificar o Estado-nação. A geografia positivista, baseada no método indutivo, era utilizada neste momento como um instrumento de legitimação das ações do poder. Nesse sentido a geografia passa a ser ensinada nas escolas com base nessa relação de poder, exaltando a idéia de patriotismo, militar, ou seja, saber reconhecer as fronteiras, identificar os recursos naturais, tendo a cartografia como um instrumento importante nesse processo, o que ajuda a corroborar com a delimitação e expansão das fronteiras que se davam nesse momento da história. Sobre este aspecto Ariovaldo U. de Oliveira ressalta que:

Todos conhecemos o papel da escola como aparelho ideológico a formar/fazer "as cabeças" das crianças. Definir e produzir uma "ideologia patriótica e nacionalista" tem sido o papel do ensino da geografia na escola (e seguramente, também da história). Uma exaltação aos atos daqueles que estão no poder do Estado. (OLIVEIRA, 2008, p. 135)

Com o desenvolvimento de novas técnicas e com a necessidade de elaboração de leis e modelos para se configurar como ciência, a geografia passa a sofrer influências neopositivistas em meados do século XX, deste modo os geógrafos buscaram elaborar análises diferentes da Geografia Tradicional, utilizando-se de índices e gráficos, planos, baseando-se no método hipotético-dedutivo, continuando como uma ciência de síntese, normativa, não avançando muito na libertação da geografia, permanecendo como instrumento de poder utilizado principalmente pelo Estado, sem a elaboração de análises críticas. E isso se reflete no ensino da geografia na escola, somando-se à geografia tradicional abordagens numéricas da população e análises regionais pautadas em um inventário dessas áreas delimitadas. No Brasil esse momento está relacionado com o período da ditadura militar, onde essas abordagens numéricas e normativas contribuíam para exaltar o nacionalismo e o "progresso", alienando os indivíduos da realidade.

Contudo, negando o método e as ideias elaboradas pela Geografia Teórico-quantitativa surge a Geografia Crítica, baseando-se principalmente no materialismo histórico dialético como método, buscando analisar as estratégias, os conflitos e as contradições promovidos pelo capital materializados no espaço. Ou seja, essa nova abordagem vem subverter a idéia da geografia como instrumento de poder utilizado pelo Estado, e pelos demais agentes hegemônicos, deste modo, como possibilidade de compreensão do mundo em sua totalidade. Segundo Ariovaldo U. Oliveira:

A incorporação da dialética, como método de investigação, tem permitido que a geografia recupere a visão do todo perdida pelo e no positivismo e não recuperada no neopositivismo, senão no plano abstrato e idealista. (OLIVEIRA, 2008, p. 140)

Mas essa geografia crítica não tem a mesma penetração no ensino escolar, tal qual na universidade, pois a compreensão da realidade pela sociedade afeta diretamente as relações de poder já estabelecidas pelo capital, perpetuando-se assim a geografia positivista e neopositivista, que se baseia na descrição dos lugares e regiões e 
se legitima através de gráficos, tabelas e mapas. Acerca deste discurso tradicional perpetuado no ensino escolar, José Willian Vesentini reflete:

Mas esse discurso tradicional é ainda eficaz? Sabemos que os meios de comunicação de massa já se apropriaram dele, bem ou mal até o dinamizaram, já que podem mostrar imagens e informações mais atuais. (VESENTINI, J.W., 2008, p. 110)

A partir deste distanciamento entre a geografia escolar e a geografia como ciência surge outro questionamento: Por que esse pensamento crítico desenvolvido nas universidades não transborda para o ensino escolar?

O que observa é que os motivos são diversos, mas ocorre principalmente pela manutenção das estruturas tradicionais, como exemplo os livros didáticos, que continuam trazendo temas para serem memorizados e não discutidos; professores que apenas acompanham os livros didáticos, os quais não desenvolvem autonomia para pensar acerca de determinado tema; a intensão de apender para passar no vestibular e não para compreensão da realidade; a falta de articulação entre pesquisa e ensino nos cursos de geografia; entre outros aspectos. De acordo com István Mészaros:

O impacto da incorrigível lógica do capital sobre a educação tem sido grande ao longo do desenvolvimento do sistema. Apenas as modalidades de imposição dos imperativos estruturais do capital no âmbito educacional são diferentes, em relação aos primeiros e sangrentos dias da "acumulação primitiva", em sintonia com as circunstâncias históricas alteradas. (MESZÁROS, 2008, p. 35)

Em relação aos livros didáticos, como afirma Ariovaldo Umbelino de Oliveira (2008), estes são adotados como cartilhas por um grande contingente de professores do ensino escolar, os quais não conseguem se desprender deste material para extrapolar o conhecimento, não propiciando nem possibilitando a construção de um pensamento crítico por parte dos professores e consequentemente pelos alunos. De acordo com Antônio Carlos Robert de Moraes (2008), este quadro se consolida em função de obstáculo dos baixos salários e condições precárias de trabalho, elevadas cargas horárias, o que dificulta ultrapassar as barreiras implantadas, em busca de uma renovação do ensino da geografia. Muitas vezes é mais simples para o professor transmitir aquelas informações já prontas e acabadas que se encontra em manuais e cartilhas, utilizando-se de exercícios repetitivos e de memorização, do que promover uma construção das idéias e uma discussão sobre um tema a partir da vivência dos alunos, pois desta forma as deficiências do professor ficarão mais evidentes.

Outra forma de perpetuação do ensino desta geografia tradicional se dá em função das provas de ingresso às universidades, os vestibulares, que continuam trazendo questões remetentes a essa geografia descritiva e sintética, e não de uma geografia analítica, corroborando desta forma com a estrutura dos livros didáticos. Com isto, principalmente no ensino médio, são elaboradas apostilas pelos próprios professores de geografia para que o aluno saiba responder a prova baseando-se em questões dos anos anteriores, na maioria das vezes não ensinando o aluno a pensar a respeito de um determinado tema.

Já em relação ao ensino da geografia nas universidades para a formação de professores, observam-se dois problemas. Primeiro é, em muitos casos, a desarticulação da pesquisa e do ensino da geografia, visto que há uma tendência de valorização do bacharelado em relação à licenciatura, até mesmo pela própria atuação dos professores universitários que se dedicam bastante a seus projetos de pesquisa, cada vez mais se especializando em suas áreas. Então, identifica-se que em alguns casos os professores não atentam para o fato que estão formando futuros professores do ensino básico, e que esses alunos precisam além de pesquisa, também saber 
ensinar o que se é pesquisado, ficando a prática pedagógica a cargo das disciplinas específicas da área de educação. O outro problema está relacionado ao ensino de geografia para os alunos de pedagogia, aqueles que quando formados ensinarão os fundamentos da geografia das primeiras séries do ensino fundamental. Esses futuros professores, em seu processo de formação, vão ter cerca de duas disciplinas de geografia durante todo o curso de pedagogia para poder ensinar nas escolas a base da geografia que se ensinará nas séries posteriores. Ou seja, na maioria das vezes esses graduandos tendem a aprender a geografia de forma superficial, ou mesmo repassam aquilo que foi ensinado no ensino médio, necessitando assim ter o livro didático como o estruturador do seu trabalho, e muitas vezes a única fonte do seu conhecimento, que será transmitido de forma mecânica e com a elaboração de graves equívocos em relação aos conteúdos. Nesse sentido Rafael Straforini afirma que:

A crise no ensino da Geografia, é, enfim, a materialização da não coerência dos pressupostos teórico-metodológicos da própria disciplina geográfica com os da Educação, uma vez que na prática educativa elas caminham no sentido oposto, ou seja, quando os professores primários dominam os avanços teóricos-metodológicos da educação, não dominam da Geografia e viceversa. (STRAFORINI, 2008, p. 72)

Diante deste quadro, volta-se à questão inicial: Quais as perspectivas teórico-metodológicas para o ensino da Geografia no século XXI? É preciso ter em mente que o ensino da geografia pode deixar ser um instrumento de dominação e se tornar um instrumento de libertação partindo do pressuposto que para isso a abordagem deve se dar de forma crítica, possibilitando o desvendar da realidade a partir da construção do conhecimento, ou seja, com elaborações de análises mais profundas dos conflitos e das relações sociais que se materializam no espaço. A partir deste conhecimento a geografia se apresenta como a possibilidade do individuo se tornar cidadão, agindo com consciência da realidade, e não de forma alienada se submetendo às estratégias do capital. De acordo com Milton Santos a cidadania pode ser entendida como:

(...) uma lei da sociedade que, sem distinção, atinge a todos e investe cada qual com a força de se ver respeitado contra a força, em qualquer circunstância. A cidadania sem dívida se aprende. É assim que ela se torna um estado de espírito, enraizado na cultura. É, talvez, nesse sentido, que se costuma dizer que a liberdade não é uma dádiva, mas uma conquista, uma conquista a se manter. Ameaçada por um cotidiano implacável, não basta à cidadania ser um estado de espírito ou uma declaração de intenções. Ela tem o seu corpo e seus limites como uma situação social, jurídica e política. Para ser mantida pelas gerações sucessivas, para ter eficácia e ser fonte de direitos, ela deve se inscrever na própria letra das leis, mediante dispositivos institucionais que assegurem a fruição das prerrogativas pactuadas e que sempre haja recusa, o direito de reclamar e ser ouvido. (SANTOS, 2007, p. 19)

Nesse sentido, a cidadania tanto pode, como deve ser construída nas escolas, à medida que se incentiva a compreensão de mundo a partir de uma análise crítica, transformando alunos em cidadão, por saberem pensar e questionar acerca da realidade. Deste modo, as perspectivas teórico-metodológicas para o ensino da geografia não podem estar pautadas na indução ou até mesmo no método hipotético-dedutivo, baseadas na descrição e na criação de verdades absolutas. Esses elementos trabalhados pela geografia tradicional devem servir como componentes iniciais da análise geográfica, ou até mesmo como instrumentos para uma análise mais aprofundada e não como o fim. O mapa, por exemplo, tão caro à geografia, instrumento de análise de extrema relevância para o estudo geográfico, deve ser utilizado como uma referência para a área a ser analisada, podendo-se obter através dele várias informações importantes para a análise espacial, como fonte de compreensão das escalas, mas o material cartográfico não deve ser o produto final de uma análise geográfica, visto que a espacialização de dados, mesmo com todo empenho, é genérica, não conseguindo expressar a realidade em uma totalidade. 
Atualmente, frente a novas técnicas como o Sistema de Informação Geográfica (SIG), está havendo uma retomada da elaboração de mapas por geógrafos nas universidades, podendo este ser um importante instrumento tanto para as pesquisas, como para o ensino da geografia, contudo é preciso frisar a necessidade de elaboração de análises acerca desses mapas e dos dados que os compõem, ou seja, utilizá-los como um instrumento para a análise espacial. Nesse sentido Ana Fani A. Carlos afirma que:

No plano do conhecimento, deparamo-nos com a produção de um saber técnico que tem contribuído para o sombreamento da realidade ao invés de iluminar as situações que bloqueiam as vias capazes de superar as contradições vividas em nossa sociedade. (CARLOS, 2009, p. 74)

Deste modo, o ponto de partida para se construir uma geografia escolar consolidada em uma perspectiva crítica, deve-se estar baseado na formação e capacitação dos professores, visto que, como afirma Rafael Straforini, “o referencial teórico-metodológico do professor é extremamente importante, pois é ele que vai conduzir toda a sua prática pedagógica." (STRAFORINI, 2008, p.72).

Mas como isto é possível? Como formar bons professores de geografia mesmo diante desta quantidade enorme de informações produzida sobre as transformações espaciais em âmbito global, e que circulam na velocidade do instante?

O professor de geografia assume um papel muito importante dentro da escola. Ele é conhecido como aquele que sabe de tudo que acontece no mundo, e isso contribui para a necessidade de uma contínua atualização de seus conhecimentos, além de estar atento nos fatos que viram notícia, pois provavelmente os alunos trarão esses assuntos para a sala de aula.

As notícias pelo mundo sempre podem virar o assunto da aula, e isso é um desafio e uma responsabilidade para o professor. Como trabalhar esses acontecimentos atuais atrelados ao conteúdo e a teoria geográficos? Muitas vezes isto aparece como um problema para o professor de geografia, mas na verdade pode ser a solução! Fazer a associação das notícias do momento com os conteúdos pode tornar a geografia a disciplina mais interessante e mais fácil de compreender, pois as notícias fazem parte do cotidiano da sociedade, alcançando os alunos, mesmo que eles estejam distantes do fato ocorrido. O intuito é de partir de um conhecimento prévio dos alunos para poder chegar ao objetivo da aula.

Mas para isto é preciso entender que informação e conhecimento são distintos. Como constantemente é dito e reproduzido, vive-se hoje na era da informação, mas isso não quer dizer que necessariamente se produz mais conhecimento. A informação é na maioria das vezes um raciocínio pronto e acabado, difundido não necessariamente com o intuito de produzir conhecimento. Contudo a informação poder ser o ponto de partida para a produção de conhecimento, mas para isto é preciso que haja um esforço cognitivo para que se possa refletir acerca de informações, com auxílio de um acúmulo de outros saberes, para que se possa produzir conhecimento. Na maioria das vezes a informação não é transmitida por completo pelos meios de comunicação, explicando os processos e as contradições dos fatos, pelo contrário, na maioria das vezes são colocadas como assertivas, como a única verdade, sem um aprofundamento maior para que se possa compreender melhor os fatos. Deste modo, a geografia tem um papel ainda maior nesta "era da informação", pois como disciplina e ciência, pode contribuir como embasamento teórico-metodológico para se compreender os fatos noticiados em uma velocidade cada vez mais ligeira e de forma efêmera pelos diversos meios de comunicação. De acordo com Milton Santos (2007): 
Uma visão mais abrangente das coisas e dos fenômenos acaba por ser negada aos cidadãos comuns, em vista da concentração da mídia, de sobrecarga de informações irrelevantes e da tendência a apenas ampliar certos aspectos da realidade, cuja escolha para a exibição pública é. Com frequência, ligada ao mundo da política e dos interesses. (SANTOS, 2007, p. 30)

Não é possível, nos dias de hoje em que a informação circula num tempo veloz, fazer uma geografia desconectada da realidade, a transformação real da sociedade e do espaço exige a transformação da Geografia (CARLOS, 2009). Na verdade, o professor de geografia deve se utilizar dessas informações como instrumento no processo de ensino-aprendizagem, sendo esta uma possibilidade de articulação do conteúdo da disciplina com as informações que os alunos têm acesso cotidianamente.

A permanente atualização e a criatividade do professor têm um papel muito importante neste processo de compreensão do todo. O professor de geografia não pode se bastar em transmitir aquelas informações já prontas e acabadas que se encontra em manuais e cartilhas, utilizando-se de exercícios repetitivos e de memorização. É preciso promover a construção de ideias e discussões sobre um tema a partir da vivência dos alunos, pois os alunos não irão entender o porquê de estudar geografia. É necessário estabelecer uma geografia analítica, possibilitando o aluno entender os problemas, os fatos, o processo, e a partir disto discutir e buscar soluções. Ao aprender a fazer análises dos fenômenos espaciais, o aluno pode questionar e buscar compreender os novos acontecimentos que se dão no mundo em diversas escalas, a partir do embasamento dado pelo professor de geografia. Uma perspectiva para a análise geográfica atual é posta por Ana Fani A. Carlos, quando apresenta o espaço como possibilidade de compreensão do mundo contemporâneo, visto que:

O espaço se apresenta como revelador das relações sociais; tanto no que se refere à sua produção quanto ao caminho de sua reprodução. Desta forma, se esclarece o caminho que conduz à construção da definição do espaço como condição/meio e produto da reprodução social. (CARLOS, 2009, p. 78)

Deste modo, o espaço se apresenta como totalidade, sendo esta a categoria que ganha destaque para o entendimento da geografia contemporânea. Contudo, ela traz consigo toda a complexidade das articulações entre diversas escalas espaço-temporais, requerendo um estágio cognitivo mais elaborado, por parte os alunos, para conseguir alcançar essa compreensão. No entanto, essa perspectiva do espaço como totalidade deve estar bem construída no conhecimento dos professores, mesmo que eles trabalhem as diferentes escalas em momentos distintos do ensino-aprendizagem, de acordo com a faixa dos alunos. É preciso desenvolver o processo de ensino-aprendizagem da geografia escolar tendo como o objetivo maior a compreensão do espaço como totalidade.

Mas não só a compreensão do espaço como categoria de análise irá dá suporte ao conhecimento dos professores de geografia do ensino básico, também é de suma importância o aprofundamento das demais categorias de análise estruturantes da geografia, território, lugar, região e paisagem, visto que a compreensão dessas categorias, e dos seus diversos conceitos, possibilita aos futuros professores uma maior capacidade de discutir e analisar os diferentes temas da geografia e além da relação dinâmica entre sociedade-natureza, que produz e reproduz diferentes espaços. Uma melhor compreensão dessas categorias possibilita um maior domínio dos conteúdos a serem trabalhados, articulando o produto da geografia como ciência à geografia escolar, aproximando as diferentes abordagens de uma mesma realidade, e a compreensão da diversidade das escalas espaço-temporais.

Entretanto, essa proposta de aprofundamento teórico-metodológico pautado nas principais categorias de análise da geografia não é nenhuma novidade. Esta possibilidade está presente como parte das diretrizes dos 
Parâmetros Curriculares Nacionais de Geografia, para serem trabalhadas desde o início do ensino fundamental.

No que se refere ao ensino fundamental, é importante considerar quais são as categorias da Geografia mais adequadas para os alunos em relação a essa etapa da escolaridade e às capacidades que se espera que eles desenvolvam. Assim, espaço deve ser o objeto central de estudo, e as categorias território, região, paisagem e lugar devem ser abordadas como seu desdobramento. (PCNs, p. 27)

Contudo, apesar desta abordagem ser proposta pelos PCNs, permanece, no âmbito da formação dos professores de geografia uma tendência de reprodução da informação e não a produção do conhecimento, isto devido à dificuldade de articulação do embasamento teórico-metodológico com a prática pedagógica.

A prática pedagógica no século XXI não necessariamente precisa estar pautada na utilização desenfreada de novas técnicas e tecnologias. Estas podem e devem ser utilizadas como instrumentos pedagógicos que auxiliem no processo de ensino-aprendizagem, pois, de fato, elas não substituem a relação professor-aluno na produção de conhecimento, apenas contribuem, não sendo a única maneira de articulação do embasamento teórico-metodológico com a prática pedagógica no processo de ensino-aprendizagem.

Deste modo, uma possibilidade de abordagem dos temas e conteúdos geográficos articulando a prática ao embasamento teórico-metodológico, que auxilie possibilite a compreensão da geografia a partir das categorias de análise, buscando a compreensão da realidade, pode ser iniciada a partir da análise da paisagem como prática pedagógica.

Ana Fani A. Carlos, ao refletir sobre a cidade, traz uma boa discussão sobre a paisagem como reveladora dos antagonismos e das contradições inerentes ao processo de produção do espaço num determinado momento histórico (2005). Ela afirma que a observação da paisagem expressa o fato de que o espaço se produz desigualmente. Nesse sentido, a paisagem pode ser tratada como o ponto de partida para a compreensão da dinâmica espacial, visto que a leitura da paisagem revela e resgata diferentes momentos históricos compostos de estruturas sociais, políticas e econômicas distintas, compondo um mosaico diacrônico que configura o espaço expresso nessa paisagem, pois:

A paisagem é uma forma histórica específica que se explica através da sociedade que a produz, num produto da história das relações materiais dos homens que a cada momento adquire uma nova dimensão. (CARLOS, 2005, p. 43)

E nesse sentido Antônio Carlos R. de Moraes corrobora com a ideia quando ele afirma que:

Todos sabemos que as formas espaciais são produtos históricos. O espaço produzido é um resultado da ação humana sobre a superfície terrestre que expressa, a cada momento, as relações sociais que lhe deram origem. Nesse sentido, a paisagem manifesta a historicidade do desenvolvimento humano, associando objetos fixados ao solo e geneticamente datados. Tais objetos exprimem a espacialidade de organizações sócio-políticas específicas e se articulam sempre numa funcionalidade do presente. Aparentemente formas inertes, possuem conteúdo, o poder de influir na dinâmica da sociedade. (MORAES, 2005, p. 15)

Deste modo, a análise da paisagem possibilita que o processo de ensino-aprendizagem da geografia parta de conhecimentos prévios dos alunos, de interpretações ainda sem uma determinação teórica, o que possibilita a reflexão sobre o tema a ser analisado. Ainda de acordo com MORAES (2005), "este nível primário de apropriação intelectual dos lugares gera uma "Geografia" informal, espontânea" (p. 27), pois, de acordo com Edvânia Torres A. Gomes (2007) "a paisagem não existe em si, ela só existe a partir de quem observa"(p.37). Assim sendo, este procedimento possibilita o despertar do interesse e da curiosidade em descobrir os demais elementos que irão compor esta análise inicial, a partir de uma construção elaborada pelos próprios alunos. 
A análise da paisagem possibilita a compreensão das relações e transformações que se dão no espaço, contribuindo para o desenvolvimento da percepção espacial da criança, visto que, também se pode trabalhar a ideia da paisagem como sendo o que é visto e percebido pelo indivíduo no espaço, construindo sua própria impressão do mundo que o cerca. Ainda de acordo com Antônio Carlos Robert Moraes:

A captação dos fenômenos, as formas de sua descrição e representação, os modelos para seu equacionamento analítico, os conceitos e categorias, enfim, os conductos da reflexão, tudo emana da própria vida da sociedade. São coisas gestadas pela práxis humana. A percepção do mundo tem também a sua história, que se traduz em diferenciadas formas de abordar o real e exprimi-lo. Nesse sentido, pode-se dizer que a consciência individual é um produto social, assim como a própria armação das subjetividades. (MORAES, 2005, p. 17)

Deste modo, identifica-se que a categoria de paisagem é primordial ao ensino da geografia desde as séries iniciais, contudo, é importante observar como a paisagem pode ser explorada, visto que há uma necessidade de análise dos elementos que a compõem para compreender sua dinâmica, não elaborando apenas um estudo descritivo para que seja feita a memorização, como tem sido realizado ao longo da história do ensino da geografia. Isto é evidente no seguinte trecho dos PCNs de Geografia.

No ensino, essa Geografia se traduziu, e muitas vezes ainda se traduz, pelo estudo descritivo das paisagens naturais e humanizadas, de forma dissociada do espaço vivido pela sociedade $\mathrm{e}$ das relações contraditórias de produção e organização do espaço. Os procedimentos didáticos adotados promoviam principalmente a descrição e a memorização dos elementos que compõem as paisagens sem, contudo, esperar que os alunos estabeleçam relações, analogias ou generalizações. (PCNs, p. 71)

Sendo assim, é preciso ir adiante, além da percepção inicial que a paisagem proporciona, a fim de revelar as ações que produzem o espaço e configuram a paisagem como tal, visto que a paisagem é aparentemente estática, mas ela está em uma constante dinâmica de transformação. Pois, como afirma Ana Fani A. Carlos:

A paisagem geográfica é a forma exterior, a aparência "caótica", sob qual se descortina a essência articulada e objetiva do espaço geográfico. Mas por que caótica? Porque o nível da aparência, do que se vê, é o nível do não explicado, não entendido. Esta paisagem, este "instantâneo" que surge, à primeira vista, aos olhos do pesquisador, não é estático, mas prenhe de movimento de vida, de uma vida rica de relações que o homem (o indivíduo) mantém dia após dia para se reproduzir enquanto ser humano, membro de uma sociedade e enquanto espécie.

Sob essa aparência estática se esconde e se revela todo o dinamismo do processo de existência da paisagem, produto de uma relação fundamentada em contradições, em que o ritmo das mudanças é dado pelo ritmo das relações sociais. (CARLOS, 2005, p. 38)

Nessa perspectiva, a utilização da paisagem no ensino da geografia possibilita um entendimento mais evidente e aprofundado da relação espaço-tempo e sociedade-natureza, pois através da leitura e análise da paisagem é possível perceber as interferências do homem no espaço transformando a natureza e os subsídios da natureza para as relações humanas, inter-relacionados em diferentes momentos e escalas ao longo da história, entendendo que a paisagem é dinâmica, pois segundo Edvânia Torres A. Gomes (2007), essa dinâmica elege a paisagem como filtro das ações. Desta forma está ressaltado nos PCNS que:

A análise da paisagem deve focar as dinâmicas de sua transformação e não a descrição e o estudo de um mundo estático. A compreensão dessas dinâmicas requer movimentos constantes entre os processos sociais e os físicos e biológicos, inseridos em contextos particulares ou gerais. A preocupação básica é [...] como os fenômenos que constituem a paisagem se relacionam com a vida que os anima. (PCNs, p. 74) 
Ainda segundo os PCNs, a paisagem deve ser trabalhada de maneira distinta nos dois primeiros ciclos dos subsequentes, o terceiro e o quarto ciclos. Nos dois primeiros ciclos deve-se explorar a paisagem na perspectiva do lugar, na escala local, porém não se restringindo a descrição, mas possibilitando que o aluno construa e desenvolva sua percepção, buscando as relações entre sociedade e natureza, compreendendo-as. Enquanto que no terceiro e quarto ciclos deve-se buscar uma abordagem que vá além da descrição do concreto, permeando pelo simbólico e as representações subjetivas que compõem e redefinem a paisagem e sua percepção. Essa diferenciação da abordagem da paisagem nos diferentes ciclos se dá pelo momento da aprendizagem que se encontram os alunos, em que em um primeiro momento há a necessidade de uma análise do que é mais palpável e primeiramente percebido, enquanto que à medida que vai se avançando no processo de aprendizagem, é desenvolvida a habilidade da abstração, possibilitando a compreensão do processo e não apenas do resultado, ou seja, analisando as ações que produziram a paisagem, e não apenas o que nela está impresso. Contudo, a busca por analisar a totalidade de as diversas escalas que a compõem não podem ser deixadas de lado. Segundo os PCNs:

No primeiro ciclo

Quando se estuda a paisagem local, deve-se procurar estabelecer relações com outras paisagens e lugares distantes no tempo ou no espaço, para que elementos da comparação possam ser utilizados na busca de semelhanças e diferenças, permanências e transformações, explicações para os fenômenos que aí se encontram presentes. Inicia-se, assim, um processo de compreensão mais ampla das noções de posição, sítio, fronteira e extensão, que caracterizam a paisagem local e as paisagens de forma geral. (PCNs, p. 87)

No segundo ciclo

O objetivo central é que os alunos construam conhecimentos a respeito das categorias de paisagem urbana e paisagem rural, como foram construídas ao longo do tempo e ainda o são, e como sintetizam múltiplos espaços geográficos. A paisagem local pode conter elementos fundamentais para os alunos observarem, compararem e compreenderem essas relações. É possível, a partir do estudo nessa escala, perceber como as paisagens urbanas e rurais foram se configurando e estão profundamente interligadas. Entretanto outras escalas podem ser abordadas e analisadas, já não apenas como fator de comparação [...], mas sim como conteúdos a serem aprendidos. (PCNs, p.93)

Com o desenvolvimento dos meios de informação como a televisão e a internet, milhares de paisagens passam a ser conhecidas e a fazer parte do imaginário das pessoas, mesmo sem terem sido vivenciadas e percebidas em loco. Deste modo, o uso dessas tecnologias pode contribuir para a compreensão do espaço mundial em diversas escalas, por, de certa forma, já haver uma familiaridade dos alunos com essas paisagens veiculadas pelos meios de comunicação, exprimindo símbolos e referências de diferentes locais, como também da homogeneização imposta pelo processo de globalização. Em muitos casos será preciso desconstruir essas imagens e estereótipos, possibilitando uma análise crítica acerca da produção dos espaços.

Nesse contexto, a análise da paisagem como prática pedagógica pode ser realizada a partir de diversas abordagens e com a utilização de diferentes instrumentos de ensino, desde fotografias, filmes, notícias, até o trabalho de campo, possibilitando a análise da paisagem e compreensão espacial em diferentes escalas. $\mathrm{O}$ trabalho de campo continua sendo de suma importância para a geografia, pois possibilita que os alunos percebam o espaço, muitas vezes já conhecido, em uma outra perspectiva, não como algo estático, mas buscando compreender sua produção, as contradições e sua dinâmica que podem estar "escondidas" atrás das aparências. 
Nesse sentido, surge uma demanda de uma abordagem teórico-metodológica que permita uma análise crítica da realidade, e uma prática pedagógica que possibilite desvendar os processos, seja a partir de uma abordagem fenomenológica, partindo do sujeito, ou dialética, compreendendo os conflitos e as contradições no e do espaço, a fim de compreender a totalidade. Desta maneira, observa-se a necessidade de alinhar os debates das universidades com a prática pedagógica, tendo a consciência que os alunos têm a capacidade de realizar essas análises e construir este conhecimento. Mas para isso é importante que os instrumentos de trabalho, os livros didáticos, e de avaliação, os vestibulares, tragam novas propostas de abordagens da geografia, além de que o professor licenciado em geografia deve se desprender das cartilhas de ensino que reproduzem uma geografia tradicional, desconectada da realidade, e ter a consciência de seu papel de libertador das ideias na construção da cidadania, e como afirma Amélia Damiani, à geografia cabe participar enquanto pensamento/ação.

\section{REFERÊNCIAS}

BRABANT, Jean-Michel. Crise da Geografia, Crise da escola. In: OLIVEIRA, A. U.; et.al (orgs.) Para onde vai o ensino da geografia? São Paulo: Contexto, 2008.

BRASIL. Secretaria de Educação Fundamental. Parâmetros curriculares nacionais: geografia /Secretaria de Educação Fundamental. Brasília: MEC/SEF, 1998.

CARLOS, Ana Fani Alessandri. A cidade. São Paulo: Contexto, 2005.

GOMES, Edvânia Torres Aguiar. Recortes de paisagem na cidade do Recife. Recife: Massangana, 2007.

MÉSZAROS, István. A educação para além do capital. São Paulo: Boitempo, 2008.

MORAES, Antônio Carlos Robert. Renovação da Geografia e Filosofia da Educação. In: OLIVEIRA, A. U.; et.al (orgs.) Para onde vai o ensino da geografia? São Paulo: Contexto, 2008.

. Ideologias Geográficas: Espaço, cultura e política no Brasil. São Paulo: Annablume, 2005.

OLIVEIRA, Ariovaldo U. Educação e ensino da geografia na realidade brasileira. In: OLIVEIRA, A. U.; et.al (orgs.) Para onde vai o ensino da geografia? São Paulo: Contexto, 2008.

SANTOS, Milton. O espaço do cidadão. São Paulo: Edusp, 2007.

STRAFORINI, Rafael. Ensinar geografia: o desafio da totalidade mundo nas séries iniciais. São Paulo: Annablume, 2008.

VESENTINI, José William. Ensino da geografia e luta de classes. . In: OLIVEIRA, A. U.; et.al (orgs.) Para onde vai o ensino da geografia? São Paulo: Contexto, 2008. 